\title{
Consagrado a Augusto ${ }^{1}$
}

\author{
José D'ENCARNAÇÃO \\ Universidad de Coimbra \\ jde@fl.uc.pt
}

\section{RESUMO}

Propõe-se uma reflexão acerca do papel do poder político na gestão dos povos, a propósito da proclamação de Augusto como imperador. O entrelaçar dos poderes político, económico, militar e religioso há dois mil anos, como na actualidade. Analisa-se a conjuntura que levou Augusto a, pela força militar, assumir o poder, procurando, porém, camuflar a enorme mudança de regime político que protagonizara, inclusive tudo fazendo para que fosse considerado um continuador e não um revolucionário.A escolha do nome constitui, nesse aspecto, um sintoma deveras significativo: começa por ser imperator (chefe militar, para agradar aos soldados); depois, é Caesar, para acentuar, do ponto de vista jurídico e pela hereditariedade, a sua legitimidade; finalmente, Augustus assinala que os deuses estão com ele e que é, no fundo, um salvador. Não se assume como deus, mas deixa que o venerem como tal, favorecendo inclusive a criação de colégios sacerdotais nas províncias, colónias e municípios, para - através do seu culto - garantir fidelidade por todo o Império. Analisam-se, a documentá-lo, alguns textos epigráficos em que a 'consagração' é evidente.

Palavras-chave: Imperator. Caesar. Augustus. Culto imperial.

\section{To Augustus Consecrate}

\section{SUMMARY}

What about the politic power on the peoples' government? On the time of Augustus, the emperor, a great difference from today? Politics, economy, military forces, religious context - yesterday and now. Why the emperor let his people see him as a guarantee of a desirable continuity? The emperor is imperator, like a military chief; he is Caesar, because his father was the killed Cesar; and, fundamentally, he is Augustus, protected by the gods, emperor to do the best for his people!... Isn't a god, but Augustus let, without objection, that the cities organise collegia to promote his cult and image. It's also an excellent form to obtain people's fidelity, especially of the middle class, always the most important part of a local population. Some epigraphic texts are evocated to document this powerful involvement.

Key Words: Imperator. Caesar. Augustus. Imperial Cult.

Sumário: 1. Uma reflexão teórica de enquadramento. 2. A conjuntura de há dois mil anos. 3. O que fez Augusto. 4. Evidências epigráficas.

\footnotetext{
1 Esta comunicação foi pensada em forma de 'ensaio'; por esse motivo, obtida a concordância (a título excepcional, o que muito agradeço) da equipa redactorial, não se indicam notas infrapaginais, que são, de certo modo, substituídas pela inclusão, no final, da bibliografia essencial de referência. Também se reduzem ao mínimo as ilustrações, nomeadamente por estarem presentes e acessíveis nessa bibliografia citada.
} 
Quando, há tempos, divulgava pelos colegas informações bibliográficas, dei por mim a pensar na imensa plêiade de historiadores da Antiguidade que, ao longo dos séculos, se debruçaram sobre o imperador Augusto. Um documento como as Res Gestae, por exemplo, terá sido estudado até ao mais ínfimo pormenor, procurando os investigadores chegar ao significado último de cada palavra...

Senti-me, pois, imensamente pequenino no meio dessa multidão, como que sufocado pelas infindáveis prateleiras de livros e de teses que, ao longo de décadas e décadas, se foram produzindo e que eu desconheço.

E hoje, ao meditar sobre o que havia de conversar convosco, perdoar-me-ão, porque nada vou trazer de novo, a não ser uma reflexão acerca do papel do poder na gestão dos povos. Apenas um reavivar de memórias, entrelaçando o antigo com o actual, em quatro pontos.

\section{Enquadramento}

Que é o poder? Doutrinas há que o resumem ao económico, puro e duro. Mas... não é o poder o político, o dos governantes? Eles pensam que sim; mas, por detrás das suas decisões, há todo um outro mundo bem mais poderoso que eles. E, nesse outro mundo, as eternas duas forças, do Bem e do Mal, chamem-se Maçonaria e Opus Dei, exército e civis, o sagrado e o profano.

Sempre a Religião procurou aliados, sempre os outros poderes a ela se quiseram aliar também. Nos documentos da monarquia portuguesa, o monarca intitulava-se "per graça de Deus rei de Portugal e dos Algarves, daquém e dalém mar em África....". E logo nos primórdios da Cristandade, Jesus Cristo se chamou de Nosso Senhor, à imitação do imperador que era dominus noster. E, em Ravena, vemos a família imperial de cabeça envolvida por uma coroa, como também as efígies imperiais desde o século III apareciam radiadas nas moedas, eficaz propaganda para contar que o imperador detinha força emanada do Sol, Oriens Augustus. Nos séculos XVI e XVIII, as epígrafes religiosas católicas iniciam-se por $D($ (eo) $O$ (ptimo) $M$ (aximo), como, entre os Romanos pagãos, se invocava Iovi Optimo Maximo. E não repugnou aos papas do século XVIII que os fiéis se declarassem devoti numini maiestatique eius, tal qual os municipia e coloniae dos séculos III e IV o diziam ser dos imperadores revestidos de uma indiscutível aura sagrada. Religião e poder, política e religião.

\section{A conjuntura}

Vivia-se, nos finais da República romana, numa crise de que hoje bem nos apercebemos porque os sintomas são rigorosamente iguais: de um lado, os muito pobres; do outro, os muito ricos; e a classe média (como hoje), mau grado as reformas dos Gracos, integralmente esvaziada de... substância. O alistamento no exército antojava-se como o meio ideal e eficaz para se lograr uma recapitalização urgente dos proletarii. $\mathrm{O}$ exército deixou de ser temporário e passou a permanente; perdeu o carácter 
de serviço público para ser alvo apetecido de voluntários. E o general (imperator) mandava, escolhia, castigava, premiava. Exército de cidadãos não há; há os milites Caesaris, os milites Pompei, os milites mei...

Prenunciavam os escritores um messias anunciado. Por ele se ansiava. E os deuses haveriam de o trazer. Não nos admiraria, aliás, que nesse espírito messiânico reinante de um lado e doutro do Mediterrâneo, a essas vozes viessem juntar-se ecos das longínquas, é certo, mas sempre presentes palavras de Isaías (32.1-2):

"Eis que um rei reinará segundo a justiça. E os príncipes governarão com equidade. Cada um deles será como um refúgio contra o vento, um abrigo contra a tempestade, como um fio de água em terra ressequida, e como a sombra duma alta rocha em terra árida ..."

Assim o proclamara Isaías, profeta; assim o proclamava o multimilionário Cícero, no seu De Republica (5.3), que bem sentia na pele a necessidade de alguém que viesse pôr ordem na conjuntura:

"Assim como o maioral conhece a natureza do terreno e o administrador sabe de letras, mas tanto um como outro se valem do gosto pela ciência em prol da sua profissão, assim também este governante ideal de que estamos a falar se dedicará a conhecer o direito e as leis (...)"

\section{Augusto}

\subsection{A mensagem que fez passar}

E o que fez Octaviano? Venceu António e Cleópatra em Áccio - victoriam consecutus bello quod pro republica gessit in hac regione - e, junto à enseada onde jaziam no fundo os barcos inimigos, mandou erguer Nicópolis, a cidade da vitória; e na encosta do monte sobranceiro levantou monumento a consagrar essa vitória (Fig. 1), que atribuiu, no entanto, não a si, mas a Neptuno e a Marte, cujos nomes figuravam, em letras de bronze, na longa fachada monumental, junto aos esporões capturados (navalibus spoliis exornata) (Fig. 2). E apressou-se a mandar cunhar moeda em Nîmes, nela se gravando um crocodilo...

E como interpretou, afinal, esse desenlace, no momento em que se decidiu a escrever as suas Res Gestae? Proclamou-o solenemente, logo no começo da epígrafe:

"Aos dezanove anos de idade, formei um exército, por decisão particular e a expensas minhas, e com ele libertei o Estado do domínio das facções".

Libertador! Octaviano, no momento em que subiu ao trono, estava bem ciente de que tramara uma revolução, de que acabara definitivamente com o regime republicano, ainda que tudo fizesse para dar a entender que tudo ficava na mesma. Destrói em seu proveito o sistema político republicano, mas proclama o seu incondicional apego às tradições, não quer assumir títulos específicos que impliquem poderes excepcio- 
nais (a ditadura, o consulado perpétuo...) e tem a preocupação de expressamente a isso se referir demoradamente nas Res Gestae $(6.1,6.2)$ :

"Tendo o Senado e o Povo Romano concordado em que eu fosse nomeado sozinho prefeito das leis e costumes com poderes absolutos, não aceitei uma magistratura que me era conferida em contradição com os costumes ancestrais"

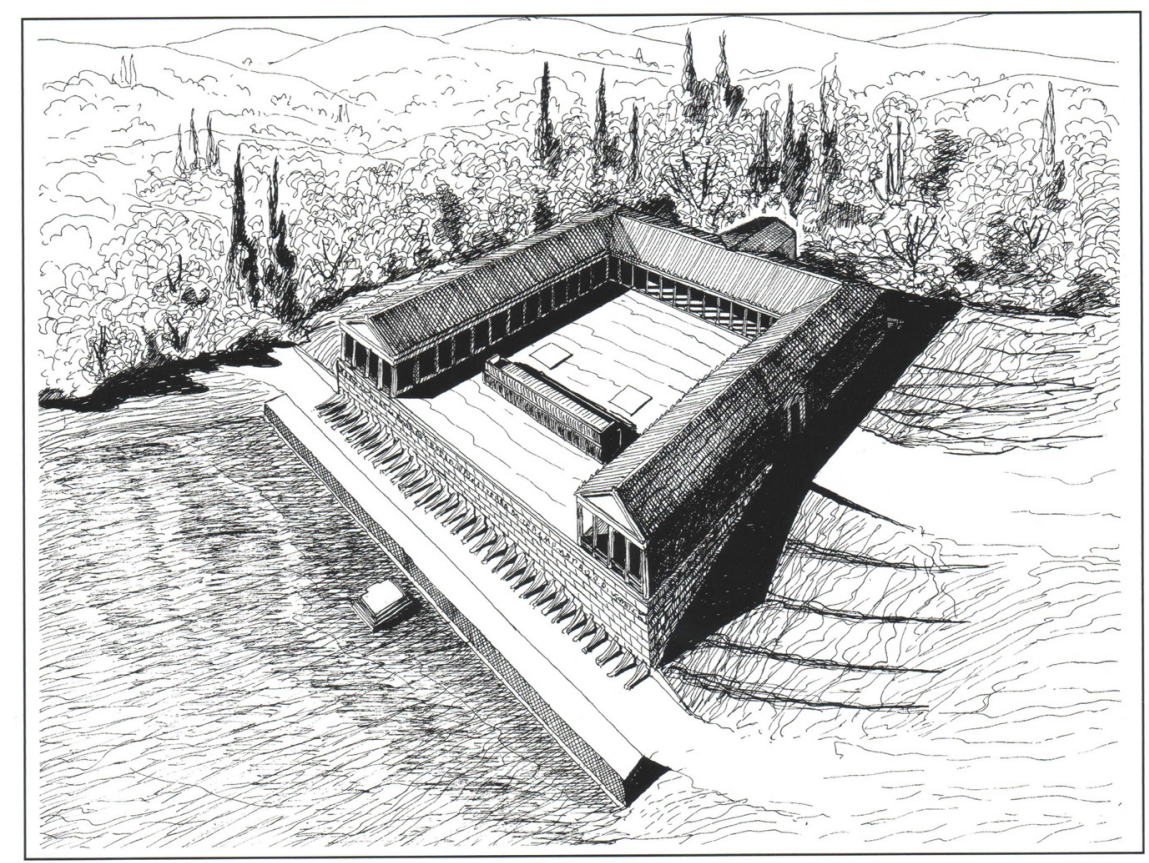

Fig. 1. Representação aproximada do trophaeum comemorativo, em Nicópolis, da batalha de Ácio, segundo os dados da escavação. Gravura retirada, com a devida vénia, da obra K. Zachos (ed.), Revealing the city of Augustus' Victory, Atenas, 2008, p. 59.

O mos maiorum. E, nesse âmbito, os escritores que, apoiado por Mecenas, soube chamar para o seu lado (Horácio, Virgílio, Ovídio, Tácito) não se cansam de dar eloquente testemunho: Augusto nada mais fez do que restaurar a República. Ou, retomando o que atrás se dizia: "Libertou o Povo do domínio das facções"! O novo Eneias, o lendário herói de quem, aliás, é considerado descendente (não é inocente o facto de, nos nichos laterais do templo a Mars Ultor, Eneias figurar entre os antepassados da gens Iulia...), também ele é especialmente protegido por Vénus! E, depois, ao longo da sua vida, nada mais fez do que representar o Povo, cumulando-o de benesses. Os jogos, as distribuições de alimentos e de dinheiro, a entrega de terras... Não o declara nas suas Res Gestae? "Proporcionei ao povo, no circo, no fórum ou nos anfiteatros, vinte e seis vezes caçadas de feras africanas, nas quais foram mortas cerca de 3500" (22.3). 


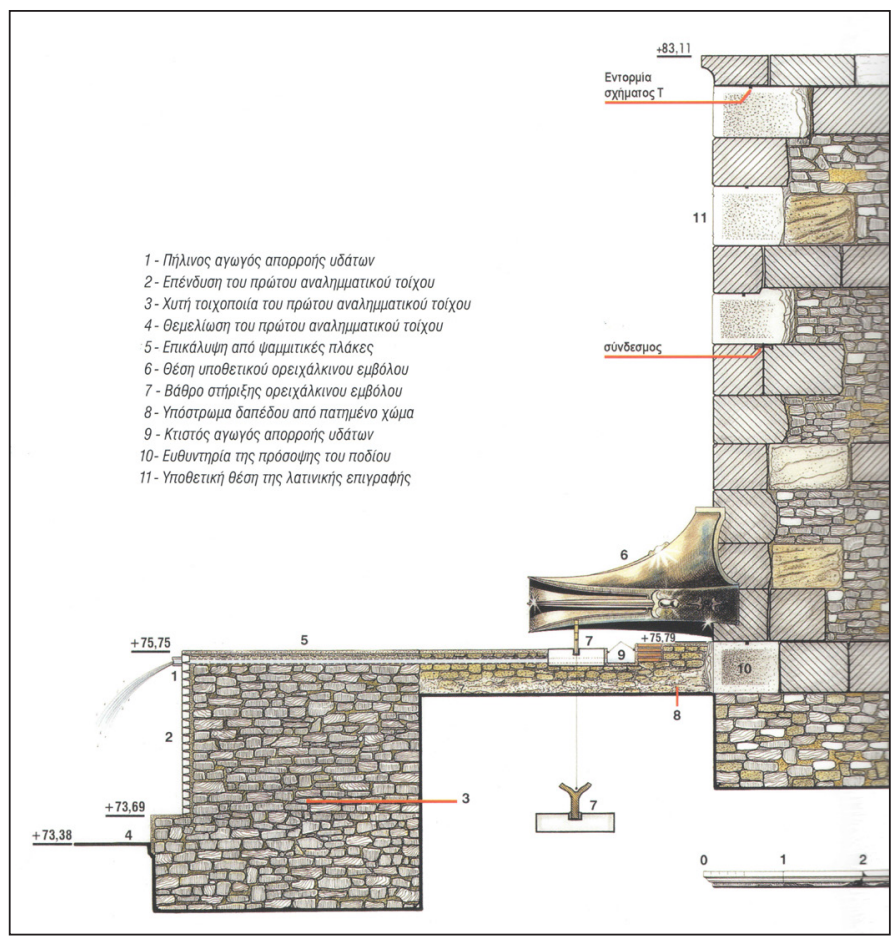

Fig. 2. Corte do muro de suporte do monumento com a localização dos esporões dos navios capturados. Gravura com a mesma procedência da anterior (p. 62), também gentilmente facultada pelo Prof. Panagiotis Doukellis.

E sendo o supremo pontificado função privilegiada de ligação entre os deuses e os homens, Augusto fez questão de só a assumir dentro da legalidade:

"Recusei ser nomeado pontífice máximo, em lugar do meu colega, ainda vivo, quando o povo me outorgava o sacerdócio que meu pai exercera"

(Res Gestae 10.2)

\subsection{O nome}

Estamos hoje, porventura, mais conscientes do significado de um nome adoptado, porque o Papa bem explicou por que quisera chamar-se Francisco.

E que nomes escolheu Octaviano? O primeiro: imperator, designação dada desde sempre aos grandes triunfadores militares e - já o vimos - Octaviano assumiu, sem receio, que fizera um golpe militar e que devia aos seus soldados o poder de que ora usufruía - e precisava de os acarinhar, para que o apoio incondicional se mantivesse.

E depois? Depois era necessária a outra justificação, mais legal, mais adequada aos olhares dos eruditos: ele era Caesar, assumia o poder porque seu pai adoptivo dele fora esbulhado por traiçoeiro assassinato. A hereditariedade impunha-se, pois, como 
justificativo. E não há em Arles a representação de um golfinho com um cometa numa das vistas? - O cometa que assinalara os funerais de César e legitimara a sucessão de Octaviano!

Finalmente, Augustus: o que aumenta, o filho dilecto dos deuses que tudo lhe proporcionaram para que, daí por diante, gerisse o mundo para bem dos seus concidadãos, ele que nada mais era do que o primus inter pares! O primeiro, porque o melhor, o mais sábio, o mais digno, o mais magnânimo, o homem providencial por que Cícero suspirara 20 anos antes! Aliás, nesse mesmo sentido se poderá incluir o culto a Ops, deusa da abundância, que Augusto fez questão de restaurar e cuja festa fixou no seu mês, Agosto, o mês naturalmente seu preferido para as grandes manifestações. E não temos no Museu do Louvre a estátua de Lívia, sua esposa, em pose e vestimenta de Ops?!...

Nas epígrafes, outras designações vão surgir. Todavia, como identificação específica, pessoal, era Imperator Caesar Augustus. Mas dos três nomes qual foi aquele que... prevaleceu? O de Augusto! E compreende-se bem porquê: porque o imperador está bem aconselhado, conhece bem a psicologia das multidões... É melhor ser bafejado pelos deuses do que apoiado pelos militares ou ostentar um alicerce familiar.

\subsection{Imperador ou deus?}

Augusto não se proclama deus. Sabe às mil maravilhas que precisa de se mostrar prudente quando pressente que lhe querem prestar culto. "Sugere, mas nada impõe. É imperador, mas evita tudo o que possa levar os outros a pensarem nele como tal. Não é deus, mas permite que vão dizendo que é" - pondera Norbert Rouland. ${ }^{2}$ Ele e os seus conselheiros têm a percepção nítida de que se está perante um deus com características bem diversas daquelas que são apanágio dos que habitam no Olimpo: a um deus erguem-se preces e ele é simplesmente honrado! No Panteão romano entrará, sim, mas pé ante pé, porque sabe quão diferente se tem de assumir em relação ao mais singelo génio das águas...

Usa, pois, da maior prudência. É, para já, filho de um deus, César: divi filius assim preconiza que se mencione nas inscrições. Não permite que seja divinizada a sua pessoa, mas - habilmente - apenas algumas das suas qualidades: o seu "génio", a sua "majestade"... Reside no Palatino, onde manda edificar todo um conjunto de edifícios consagrados a Apolo - e não se importa que lhe chamem "filho de Apolo". Aliás, há no teatro de Arles uma estátua de Augusto, mas a pose é a de um Apolo verdadeiro! Magnífico era o templo de Apolo sobre o Palatino - e a humilde casa do imperador estava... paredes-meias com ele!...

2 Rouland 1981, 245. 


\section{Evidências epigráficas}

Neste domínio, os monumentos epigráficos funcionam, mais uma vez, como veículos transmissores de um poder. Em território peninsular, poderemos começar pelo arco de Medinacelli: Numini Augusto sacrum, reza a epígrafe. Sintomático, na verdade: é Augusto ou o seu numen? Ou é o numen, a divindade, que assume as vestes imperiais?

Em Salacia (Alcácer do Sal), um indígena, Vicanus, filho de Boutius, apresenta-se como promotor de homenagem ao imperador, nos anos 5 ou 4 a.C. O lintel epigrafado a figurar no frontispício de um templo! E há que atentar no texto: todas as palavras de vasta conotação religiosa vêm aqui por extenso, para que não restassem dúvidas: o imperador é Augustus, é pontifex maxumus; detém a potestas, assim um misto de poder político e religioso, a potestade!... E o dedicante preferiu tão-somente mandar gravar SACRVM, "consagrado", por extenso, no final. Não era, decerto, sacerdote; identifica-se - e não tem pejo nisso - à maneira indígena. Não creio que deva subentender-se algo como sacrum fecit, em jeito de "tornar sagrado". Não: é mesmo "consagrado" só - deixando-nos na incerteza se é ele que se consagra juntamente com o templo que o simboliza ou se tiveram, ele e o lapicida, dificuldades na escolha do termo mais adequado e optaram por um que já era habitual tanto nas epígrafes votivas como nas consagrações aos deuses Manes...

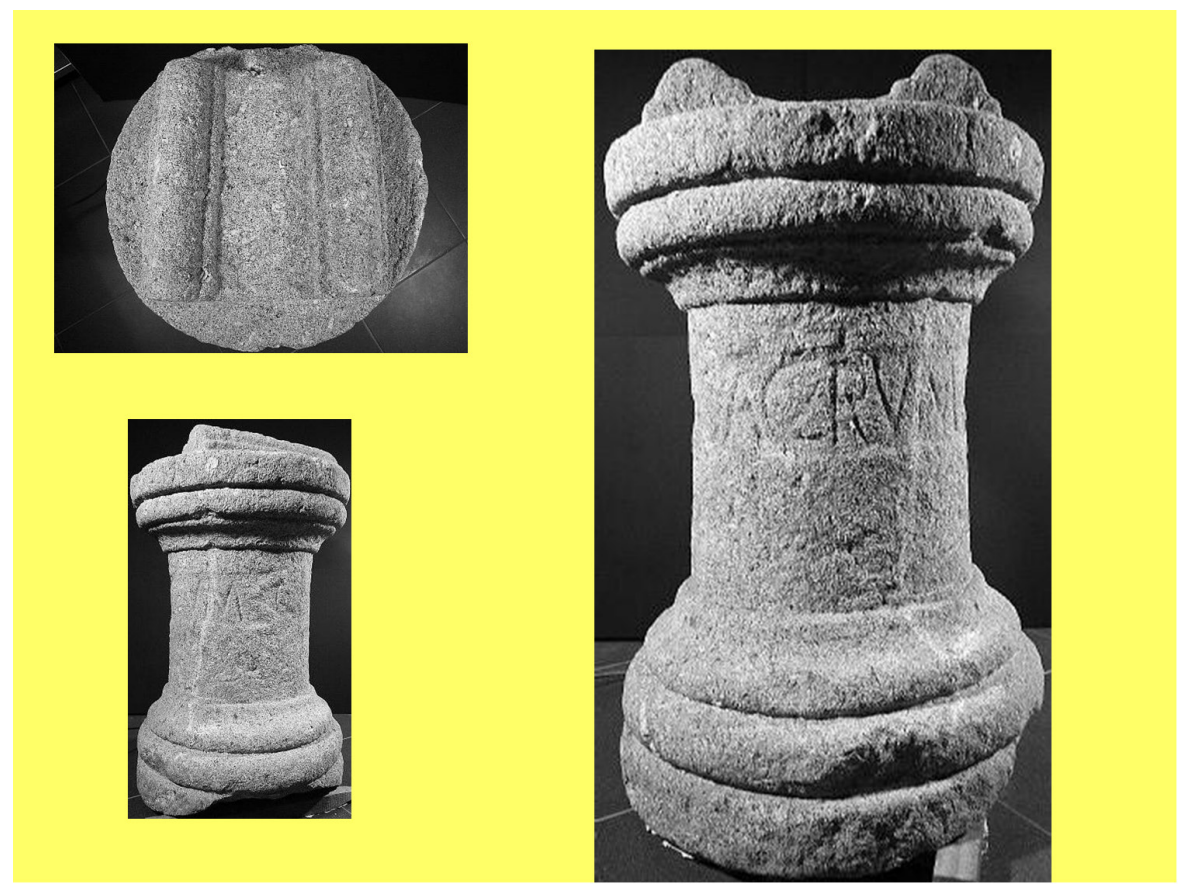

Fig. 3. Ara cilíndrica de Bracara Augusta. 
Não pode deixar-se de pôr em paralelo o texto singular desta epígrafe com a conhecida dedicatória de Gneu Calpúrnio Pisão, datada de 9/10 d.C., onde também o vocábulo sacrum surge em idêntico contexto de culto imperial. Não se trata de um altar, mas sim de amplo lintel a identificar, mui possivelmente, a torre-farol ali edificada no tempo de Augusto. Acham Carmen Fernández Ochoa, Ángel Morillo Cerdán y Ángel Villa (que minuciosamente estudaram a inscrição e o seu contexto) que, "apesar da sua sacralização ritual", a epígrafe terá, como os demais troféus erguidos aqui e além no tempo de Augusto, um "carácter simbólico ou comemorativo", "uma intencionalidade mais política do que religiosa". Permito-me apontar em sentido oposto: mais religiosa do que política!

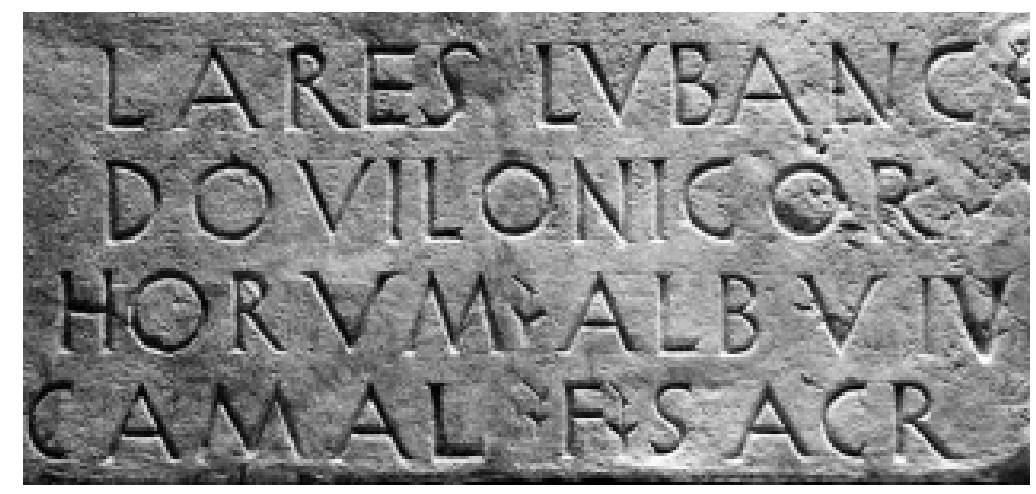

Fig. 4. Placa de Conimbriga consagrada a Lares indígenas.

E se nada poderei adiantar de concreto acerca da ara cilíndrica de Bracara Augusta, onde apenas se lê $S A C R V M$ (Fig. 3), ainda que resulte aliciante pensá-la enquadrável num contexto de ritual consagrado ao imperador, o fundador da cidade, não será despiciendo recordar o texto da epígrafe identificada em Conimbriga (Fig. 4): referemse uns Lares de epíteto tópico ou, de preferência, etnonímico: Lubanc(i?). Explicitase, de seguida, que serão protectores Dovilonicor(um) horum, "destes Dovilónicos", presumivelmente um grupo étnico (digamos assim) que teria mais do que um ramo. Mas o que, de modo especial, me interessa focar é a forma como vem referido o dedicante e o seu gesto, em tudo semelhante ao que se passa nos lintéis de Campa Torres e de Salacia: Albuiu(s) Camal(i) f(ilius) sacr(um). Está certo: poder-se-ia desdobrar sacr(avit); contudo, o paradigma ideológico subjacente permanece igual! Enquanto nas epígrafes votivas habituais temos a palavra sacrum imediatamente após a identificação da divindade, aqui vem no final, após o nome do dedicante. Em Medinaceli, em Campa Torres e em Salacia, a consagração era a Augusto; em Conimbriga, é aos Lares. Um paralelismo evidente!

\section{Em conclusão}

Teve o imperador Augusto a extraordinária perspicácia de se servir dos conceitos religiosos, aplicando-os a si, com prudência mas com eficácia extrema. Soube ocul- 
tar, assim, envolta num halo místico, a assunção de um poder absoluto, que de outra forma nunca lograria deter, numa sociedade profundamente arreigada aos princípios republicanos de vários poderes variamente partilhados. Augustus, Divi filius, pontifex maximus, dotado de tribunicia potestas, lentamente se vai deixando deificar... Um pedestal como o de Olisipo, mandado erigir Divo Augusto pelos augustales C(aius) Arrius Optatus e C(aius) Iulius Eutichus constitui uma das muitas eloquentes provas que poderiam aduzir-se a demonstrar como resultou em pleno a campanha levada a cabo por Augusto e seus adeptos fiéis: foi divus após a morte; teve colégios sacerdotais a bajulá-lo pelo Império, em todos os cantos...

Quem disse aí ser o poder político uma ilha autónoma sem templos nem cofresfortes nem auras sobrenaturais a nimbá-la? Augusto não escapou à tentação que já vinha de muito longe, perdida na neblina dos tempos. Quando desbaratou Cleópatra, poderia ter dito a algum dos seus companheiros de armas: "Eu nunca serei Ikenaton, nunca um faraó incensado!...". Se o houvesse dito, depressa as suas atitudes demonstrariam cabalmente o contrário. Faraó não foi; a província do Egipto - Aegypto capta lê-se na legenda da moeda - será entregue a um prefeito de sua confiança recrutado na ordem equestre; sabia perfeitamente que "o incenso que se evola para o altar dos deuses e dos tiranos tem sempre o mesmo perfume"; mas o importante era... que o incenso nunca faltasse! E na Hispânia, de facto, não faltou!

\section{Bibliografía}

Carvalho, H. et aliI (2006): “Altar romano encontrado em Braga”, Forum 40, 31-41. Acessível em: http://hdl.handle.net/1822/9250.

ENCARNAÇÃO, J. D’

(1984): Inscrições Romanas do Conventus Pacensis - Subsídios para o Estudo da Romanização, Coimbra. [=IRCP]. Acessível em: http://hdl.handle.net/10316/578.

(2000): "Tibério Semprónio Graco (162-133 a. C.): entre o voo das águias e a voracidade dos abutres", Espacio Tiempo y Forma, série II (História Antigua), 13, 219-228. Acessível em: http://hdl.handle.net/10316/25307.

(2002): "Convergência e cisão na génese do Império Romano", Humanitas 54, 231-243. Acessível em: http://hdl.handle.net/10316/20222.

(2013): "Salacia Imperatoria Urbs", Arqueología Iberoamericana 18, 15-24. Acessível em: http://hdl.handle.net/10316/23687.

Étienne, R. et ALII (1976): Fouilles de Conimbriga, vol. II - Épigraphie et Sculpture, Paris.

Fernández OchoA, C. ET ALII (2005): "La Torre de Augusto en la Campa Torres (Gijón, Asturias). Las antiguas excavaciones y el epígrafe de Calpurnio Pisón”, AEspA 78, 129-146.

Lesuisse, L. (1961): “La nomination de l'empereur et le titre d'imperator”, AC 30, 415-428.

Quinteira, C. - EnCARnaÇão, J. D’ (2009): “CIL II 182, de Olisipo”, Conimbriga 48 181187. Acessível em: http://hdl.handle.net/10316/13088.

Rouland, N. (1981): Rome, Démocratie Impossible? (Les Acteurs du Pouvoir dans la Cité Romaine), Le Paradou.

SAntos Yanguas, N. (2011-2012): "El culto al Emperador en la Asturias romana", Tiempo y Sociedad 6, 42-78. 